\section{É POSSÍVEL PRODUZIR ALIMENTOS PARA O BRASIL SEM AGROTÓxICOS?}

\author{
Carlos A. Lopes
}

INTRODUÇÃO O Brasil é hoje um dos maiores usuários de produtos praguicidas agrícolas - que fazem parte do complexo grupo de substâncias chamado de "agrotóxicas" - do mundo, o que pode ser explicado, pelo menos em parte, pela sua aptidão agrícola e pelo seu consolidado protagonismo como extraordinário produtor de alimentos. Não há como negar que essa evolução se deve à modernização agrícola introduzida pela "revolução verde", intensificada nas décadas de 1960 e 1970, com a recomendação de novas tecnologias que resultaram em profundas mudanças na agricultura. Por outro lado, esse rápido desenvolvimento tecnológico se deu em descompasso com o desenvolvimento humano no meio rural, em que uma parcela da população, despreparada, com pouco ou nenhuma assistência técnica, foi exposta a um grande número de substâncias químicas potencialmente tóxicas (não só de agroquímicos), gerando, assim, um efeito colateral indesejável desse processo de "modernização" [1]. É evidente que essa situação, que perdura, mas é cada vez menor em função da profissionalização do produtor que visa renda, é preocupante, e a solução tem sido buscada por recorrentes ações interinstitucionais e multidisciplinares.

A questão do uso dos agrotóxicos na agricultura tem sido alvo de constantes discussões em diferentes fóruns, científicos ou nem tanto, muitas vezes pautadas por cansativos, inocentes ou desqualificados argumentos para justificar seu uso ou sua condenação. De um lado, alguns defendem a ideia de que eles deveriam ser sumariamente banidos, pelo mal que causam à saúde humana e ao meio ambiente. E, no outro extremo, como tem sido moda no Brasil polarizar ideias, há os que contextualizam que eles são imprescindíveis para garantir o suprimento de alimento para a população. Outros, mais sensatos, acreditam que os agrotóxicos são necessários, porém seu uso indiscriminado deve ser rigorosamente combatido para o bem das sustentabilidades econômica, ambiental e social da agricultura.

Mas seriam mesmo os agrotóxicos vilōes, ou seja, venenos desnecessários servindo basicamente aos interesses das multinacionais? Ou seriam aliados dos agricultores: insumos necessários para o combate das pragas que destroem as lavouras? A intenção deste artigo não é alimentar essa polêmica, mas sim deixar alguns pontos para reflexão no sentido de contribuir para que o leitor tenha condições de formar sua própria opinião sobre o tema, obviamente sem a pretensão de esgotá-lo. Se for notado nele algum viés, não foi intencional, a não ser pelo lado da busca de visão pautada pelo rigor da pesquisa científica, com respeito às eventuais correntes ideológicas que perigosamente podem nos afastar da verdadeira ciência. Adam Smith, economista e filósofo escocês do século XVII, já disse que "a ciência é o grande antídoto do veneno do entusiasmo e da superstição”.

A QUESTÃO CONCEITUAL DOS AGROTÓXICOS O uso de agrotóxicos no Brasil é regido pela Lei No 7.802, de 11 de julho de 1989 (Lei dos Agrotóxicos), regulamentada pelo Decreto no 4.074/2002. De acordo com o seu Artigo $1^{\circ}$, esta lei versa sobre a "pesquisa, a experimentação, a produção, a embalagem e rotulagem, o transporte, o armazenamento, a comercialização, a propaganda comercial, a utilização, a importação, a exportação, o destino final dos resíduos e embalagens, o registro, a classificação, o controle, a inspeção e a fiscalização de agrotóxicos, seus componentes e afins" [2].

Em seu Artigo 2o, para os efeitos desta Lei, consideram-se: "I agrotóxicos e afins: a) os produtos e os agentes de processos físicos, químicos ou biológicos, destinados ao uso nos setores de produção, no armazenamento e beneficiamento de produtos agrícolas, nas pastagens, na proteção de florestas, nativas ou implantadas, e de outros ecossistemas e também de ambientes urbanos, hídricos e industriais, cuja finalidade seja alterar a composição da flora ou da fauna, a fim de preservá-las da ação danosa de seres vivos considerados nocivos (grifo próprio); b) substâncias e produtos, empregados como desfolhantes, dessecantes, estimuladores e inibidores de crescimento; II - componentes: os princípios ativos, os produtos técnicos, suas matérias-primas, os ingredientes inertes e aditivos usados na fabricação de agrotóxicos e afins."

Certamente, boa parte das divergências sobre esse tema se deve à falta de clara definição do termo oficial "agrotóxico e afins". Anteriormente chamado de "defensivo agrícola", esse grupo de produtos e agentes é informalmente referido como "praguicida" ou "pesticida". Mais recentemente, recebeu também a denominação de "produto fitossanitário com uso aprovado para a agricultura orgânica”, sutilmente usada para evitar o termo "tóxico", quando a sua finalidade é evitar as pragas em sistemas orgânicos de produção.

Peres e colaboradores [3] já alertaram sobre essa fragilidade de conceitos ao declararem que "tão extensa quanto a lista de efeitos nocivos dos agrotóxicos à saúde humana é a discussão sobre a nomenclatura correta dessa gama de produtos, a qual, de acordo com os interesses de grupo (ou grupos) envolvido(s), pode dar-lhes conotações muitas vezes opostas ao sentido real”. Infelizmente quase 15 anos depois do alerta desses autores, essa fragilidade persiste.

Dessa maneira, mesmo os movimentos contrários ao seu uso, como a "Campanha permanente contra os agrotóxicos e pela vida" (http://contraosagrotoxicos.org/), encontram sérios problemas para se expressar diante de algumas situaçōes, dificultando, assim, até louváveis ações em prol da saúde da população. Por exemplo, será que, ao recomendarem à população alimentos oriundos de sistemas orgânicos para evitar a exposição do consumidor aos resíduos de substâncias químicas, alertariam também para o perigo de nadar em uma piscina tratada com cloro que, por definição, é considerado um agrotóxico, se usado nas lavouras? Ou mesmo usar, no preparo de 
alimentos, uma água que se tornou potável pelo tratamento químico? Ou utilizar um antibiótico ou fungicida, de mesma composição química que produto usado na lavoura (agrotóxicos), para combater uma infecção, e que neste caso são chamados de "remédios"? Ou leite de vaca para combater o oídio das cucurbitáceas, doença causada por um fungo? Em suma, é praticamente impossível produzir qualquer alimento totalmente isento do que hoje é chamado de "agrotóxico e afins" que, pela sua definição, nem sempre é de uso agrícola e nem sempre é veneno. E, por falar em veneno, não há como não recorrer à célebre frase de Paracelsus, médico suíço da Idade Média: "todas as substâncias são venenosas. $\mathrm{O}$ que diferencia um veneno de um remédio é apenas a dose”.

SÃO OS AGROTÓXICOS REALMENTE VILÕES? Se, simplificadamente, considerarmos como o tema principal neste artigo apenas o grupo de agrotóxicos usado na agricultura mais vilanizados, ou seja, o das substâncias químicas comercializadas por grandes empresas e aplicadas para controlar as pragas das lavouras (insetos, bactérias, fungos, nematóides e plantas daninhas), há evidências cada vez maiores que, mesmo pequenas doses de grande parte deles - e de outros produtos químicos de diferentes naturezas (como fumaça, materiais de limpeza e medicamentos) - podem ter efeito deletério de longa duração na saúde das pessoas. Isso implica em alertar que é importante que cada ator envolvido nos processos correspondentes (desde a produção, transporte, armazenamento, comercialização, aplicação e consumo) esteja consciente da dose e a toxicidade de cada produto, para que esse efeito deletério seja dimensionado e minimizado.

No Brasil, a Agência Nacional de Vigilância Sanitária (Anvisa) classifica esses produtos em quatro classes considerando seus efeitos agudos: I - Extremamente tóxicos (Faixa vermelha); II - Altamente tóxicos (Faixa amarela); III - Moderadamente tóxicos (Faixa azul); e IV - Pouco tóxicos (Faixa verde) [4].

Em sua análise de resíduos em um grupo de alimentos, a Anvisa monitora periodicamente dois tipos de não conformidade. $\mathrm{O}$ primeiro é relacionado com a detecção de qualquer quantidade de produto (agrotóxico) não registrado para uso naquela espécie de alimento. $\mathrm{O}$ segundo se refere à detecção de produto registrado, porém encontrado em níveis acima do limite definido para aquele produto. O primeiro é mais frequente nas frutas e hortaliças, mas ambos são igualmente indesejáveis.

Aos que sistematicamente procuram demonizar os agrotóxicos e as empresas que os produzem, é bom esclarecer que:

1. Os agrotóxicos são produtos legais, regulamentados pela Lei $\mathrm{n}^{\circ}$ 7.802/89, "que julga a importância do seu uso racional e de forma sustentável, ou seja, que não causem danos ao meio ambiente e à saúde humana";
2. A contaminação de alimentos não é somente de origem química. A contaminação biológica, de ação rápida e perigosa, também merece constantes alertas e ações em qualquer modelo agrícola. Esta se dá pelo uso de água contaminada durante a produção, pela lavagem ou pela higienização precária no processamento, embalagem e transporte. A contaminação química, a não ser que a aplicação seja muito abusiva e o produto muito tóxico, é geralmente cumulativa, podendo se manifestar somente após vários anos. Estudos de intoxicação são normalmente complexos e de longa duração;

3. A maneira de as plantas se defenderem quando sofrem o ataque de pragas, que são mais frequentes em sistemas orgânicos de produção, é sintetizando grande número de substâncias químicas, muitas ainda desconhecidas, que são os "praguicidas" naturais. Essas substâncias podem ser tóxicas também aos seres humanos, em escala até maior do que muitos agrotóxicos usados na agricultura convencional [5]; 4. A agricultura orgânica, alternativa recomendada (de forma inocente ou com finalidade de marketing) para desvincular o produto dos resíduos de agrotóxicos, de fato, também faz uso desses produtos, mesmo que de forma limitada. Na seção III da Instrução Normativa 17/2014/Mapa, que trata o manejo de pragas, o parágrafo $3^{\circ}$ do artigo 106 diz que "Fica permitida a utilização dos agrotóxicos e afins registrados no Ministério da Agricultura, Pecuária e Abastecimento, cujas substâncias ativas constem no Anexo VII desta Instrução Normativa" [6].

\section{OS AGROTÓXICOS SÃO MESMO NECESSÁRIOS PARA} A PRODUÇÃO DE ALIMENTOS? As frutas e as hortaliças são especialmente afetadas por pragas que, além de reduzirem a produtividade, comprometem a aparência do produto. No Brasil e em outros países tropicais, os riscos de ocorrência e a magnitude dos danos são ainda maiores, pois o clima permite a sobrevivência dessas pragas mesmo durante o inverno, diferentemente do que acontece em países de clima temperado. Assim, essa diferença climática explica, em grande parte, a maior necessidade da aplicação dos "agrotóxicos" que, inegavelmente, são fortes aliados dos produtores no controle de insetos, patógenos e plantas daninhas. Em suma, o produtor convencional responsável não gosta de "jogar veneno" na lavoura. Ele o faz para evitar as perdas quantitativas e qualitativas que podem inviabilizar a sustentabilidade econômica da sua propriedade.

Por exemplo, algumas doenças de plantas podem causar perda total da lavoura, como a requeima da batata e do tomate causada pelo oomiceto Phytophthora infestans. Na indisponibilidade de cultivares resistentes a esta doença e na presença constante de propágulos do patógeno no ambiente, o produtor não tem outra alternativa a não ser proteger as plantas com fungicidas sempre que ocorrer condição climática favorável à doença (temperatura amena e alta umidade). Como essa condição é frequente, em especial para a cultura da batata, esse é um dilema fácil de ser resolvido pelo produtor: ou ele aplica 
o fungicida e vai dormir tranquilo ou fica exposto ao grande risco de perder a lavoura, de alto custo de implantação.

Embora a relação custo/benefício seja variável em função de vários fatores (principalmente as espécies de planta, o local de plantio e a presença histórica de pragas na região) para as condições vigentes nos Estados Unidos, Schumann e D'Arcy [7] relatam que, em média, para cada dólar gasto com fungicidas, há um retorno de mais de 14 dólares. Em países de clima tropical, esse ganho tende a ser ainda maior.

Justificada a importância do uso de agrotóxicos, certamente há que se reduzir os custos (financeiro, ambiental e de saúde humana) de seu uso, atitude que a grande maioria dos produtores empresariais já toma, por consciência ou por necessidade em função de fiscalizações diversas. A decisão de consumir produtos tratados com agrotóxicos se baseia no risco - da mesma maneira que tomamos antibióticos ou vacinas - e passa também por uma questão de confiança e da clara percepção da relação de benefício/custo.

A observância da racionalidade do seu uso, entretanto, é um desafio enorme em função da vasta área agricultável no país. Como consequência, grande número de pequenos produtores, com alta proporção de baixa escolaridade, não é devidamente atendida pela assistência técnica e pela fiscalização, de modo a proporcionar adequada produtividade pela adoção das boas práticas culturais, além de identificar as não conformidades de comercialização e uso [3].

Ajustes e certa customização são necessários, mas não há como pensar em retroceder a técnicas primitivas em prol exclusivamente do "politicamente correto" a favor dos ecossistemas, assim desqualificando tecnologias modernas e seguras, como pregam algumas correntes agroecológicas mais radicais. A ciência traz rápido e constante avanço nas diferentes áreas de atividade, e a agricultura deve seguir o mesmo rumo, o qual é um caminho sem volta. A agricultura orgânica comercial, em evidente expansão, é mais flexível na adoção de técnicas ambientalmente aceitáveis desenvolvidas pela boa pesquisa, que serve a todas as correntes de pensamento, $\mathrm{e}$ que permitem o uso dos recursos naturais em prol de nossas necessidades e nosso bem-estar. Nada contra, porém, aos que preferem manter contato íntimo com a natureza, sem ambiçōes financeiras na atividade agrícola. Manter usuários nos sistemas eivados de ideologias com recursos públicos, no entanto, é temerário; apoiá-los com políticas sociais, é aceitável.

Em suma, a preocupação causada pelos agrotóxicos não deveria centrar-se nos agrotóxicos em si, cujo uso é legal, porém em seu mau uso, quando são utilizados produtos não registrados (muitas vezes até contrabandeados) e quando não se respeitam dosagens e nem os períodos de carência. Quando isso acontece, muitos alimentos que vão para as nossas mesas realmente contêm resíduos indesejáveis de produtos químicos. Um paralelo pode ser traçado com as doenças humanas e as graves consequências do uso de "remédios" mal administrados para combatê-las, seja pela qualidade ou quantidade do medicamento. Em ambos os casos, seu mau uso não justifica o seu combate sistemático.
A complexidade conceitual do termo agrotóxico e das diversas formas de agricultura apresentadas até aqui é muito bem representada por Rosolem [8], quando diz que

"[...] orgânico, ou biodinâmico, tanto quanto empresarial, pode ou não ser sustentável ou saudável. A associação de sustentável, ou saudável, ou ecológico, tem sido uma ferramenta de marketing poderosa na colocação dos produtos, agregando valor e definindo grupos de consumidores. Assim, temos a liberdade de escolha ao adquirir nossos alimentos, sejam produzidos por meios ditos alternativos ou ditos tradicionais. Entretanto, é fundamental a consciência de que a associação de um tipo de produção não garante saúde ou qualidade. São coisas diferentes" [8].

PESQUISA AGRÍCOLA PARA OS ALIMENTOS MAIS SAUDÁVEIS O mote de vários grupos de pesquisa comprometidos com as cadeias produtivas é a busca constante de alternativas de controle de pragas que sejam cada vez menos dependentes dos produtos químicos. No entanto, essas alternativas devem merecer a confiança do produtor e ter custo competitivo. Até que possamos abrir mão definitivamente dos agrotóxicos, situação que, com muito otimismo, levará ainda muitos anos, é realista pensar que a Embrapa, as universidades e os institutos estaduais de pesquisa vêm diligentemente procurando essas alternativas. Tratam-se de pesquisas sobre medidas de controle pautadas em ensaios com o devido rigor científico: substituição de produtos muito tóxicos por outros menos tóxicos (químicos ou biológicos), obtenção de cultivares resistentes ou tolerantes às pragas, uso racional da água em diferentes sistemas de irrigação, rotação de culturas, vazio fitossanitário, tecnologias de aplicação de produtos, solarização do solo, correção e adubação do solo, sistemas de produção de sementes e mudas sadias, cultivo protegido, entre outras. A adoção dessas medidas dentro da filosofia de controle (ou manejo) integrado, certamente reduzirá a necessidade do uso de agrotóxicos, independente do modelo de produção (convencional, orgânico, agroecológico, biodinâmico etc.).

Em recente publicação de Lopes e Pedroso [9], a sustentabilidade de diferentes modelos de produção agrícola é discutida por especialistas de várias áreas de conhecimento atentos aos avanços científicos, normalmente pautados na segurança alimentar (oferta de alimentos em quantidade) associada a alimentos seguros (sem contaminações de diferentes tipos).

Melhores resultados poderiam advir da continuada capacitação de produtores e extensionistas nessas práticas de cultivo, muitas delas já fartamente divulgadas pela pesquisa. No que se refere à ciência básica, é necessário ainda desenvolver e aperfeiçoar técnicas de detecção de resíduos para fins de monitoramento dos alimentos, apoiar as empresas de agrotóxicos no desenvolvimento e avaliação de produtos menos tóxicos, além de incentivar e fortalecer no ambiente acadêmico a cultura da importância de produzir alimentos saudáveis. 


\section{CONCLUSÕES}

1. A informação responsável, isenta de interesses e ideologias, é importante para que se formem opiniōes sobre temas tão complexos como agrotóxicos, venenos e sustentabilidade. Assim como é bom assistir aos filmes $O$ veneno está na mesa [10] e $O$ veneno está na mesa 2 [11], de Silvio Tendler, é bom ler também o livro Agradeça aos agrotóxicos por estar vivo, de Nicholas Vital [12];

2. Não há como negar que a tecnologia agrícola avançou muito e permitiu impressionantes aumentos de produtividade em áreas pouco produtivas, como os cerrados, que hoje concorrem com significativa parcela do PIB brasileiro. Sem os agroquímicos, isso seria impossível. A agricultura menos eficiente demandaria maior área de cultivo e provavelmente resultaria em maior dano ambiental;

3. Os agrotóxicos, quando usados indiscriminadamente, oferecem sérios riscos à saúde, em especial aos agricultores, que manuseiam os produtos, e aos consumidores. Por outro lado, os benefícios do seu uso, desde que de forma racional, são inquestionáveis, independentemente do modelo de produção, seja ele convencional ou orgânico; 4. Os sistemas orgânicos de produção podem conviver harmonicamente com a agricultura convencional, desde que ambos sejam conduzidos de acordo com as boas práticas de cultivo. A agricultura convencional oferece mais segurança econômica, enquanto a produção orgânica é mais complexa, oferece mais riscos, mas é ambientalmente mais amigável.

Carlos A. Lopes é pesquisador na Embrapa Hortaliças. Doutor em fitopatologia pela Universidade da Flórida.E-mail: carlos.lopes@embrapa.br

\section{REFERÊNCIAS E SUGESTÕES BIBLIOGRÁFICAS}

1. Oliveira-Silva, J. J., Meyer, A. "Sistema de notificação de intoxicações: o fluxograma da joeira". In: Peres, F.; Moreira, J. C. (orgs.) É veneno ou é remédio?: agrotóxicos, saúde e ambiente [online]. Rio de Janeiro: Editora Fiocruz, 2003.

2. Brasil. Lei $N^{\circ} 7.802$, de 11/07/1989 (Lei dos agrotóxicos). Disponível em: 〈http://www.planalto.gov.br/ccivil_03/leis/17802.htm〉. Acesso em: 14 de julho de 2017.

3. Peres, F.; Moreira, J.C.; Dubois, G.S. “Agrotóxicos, saúde e ambiente: uma introdução ao tema". In: Peres, F.; Moreira, J. C. (orgs.) É veneno ou é remédio?: agrotóxicos, saúde e ambiente [online]. Rio de Janeiro: Editora Fiocruz, 2003.

4. Brasil - Anvisa. Classificação toxicológica. Disponível em: http:// www.aenda.org.br/painel/images/files-legislacoes/136/u/portaria-anvisa-03-1992---avaliacao-toxicologica.pdf. Acessado em: 15 de julho de 2017.

5. Winter, C. "Is organic food better for you?". WebMD, 2017. Disponível em: http://www.webmd.com/food-recipes/features/organic-food-better\#3. Acessado em: 15 de julho de 2017.

6. Brasil - Mapa. Instrução Normativa 17/2014/MAPA. Disponível em: http://biodinamica.org.br/pdf//N-17.pdf. Acesso em: 15 de julho de 2017.
7. Schumann, G. L.; D'Arcy, C. J. "Chemicals to protect plants: Pesticides". In: Schumann, G. L.; D'Arcy, C. J. Hungry planet. Stories of plant diseases. APS Press. St. Paul, MN. 2012.

8. Rosolem, C. A. "Muitas agriculturas". Agro olhar, 2015. Disponível em: http://agro.olhardireto.com.br/artigos/exibir.asp?id=314\&artigo=muitas-agriculturas. Acesso em: 17 de setembro de 2017 .

9. Lopes, C. A „, Pedroso, M. T. M. (eds. técnicos). Sustentabilidade e horticultura no Brasil: da retórica à prática. Embrapa, Brasília, DF. 436 p. 2017.

10. Tendler, S. O veneno está na mesa. 2011. Disponível em: https://www. youtube.com/watch?v=fyvoKljtvG4

11. Tendler, S. O veneno está na mesa 2. 2014. Disponível em: contraosagrotoxicos.org/o-veneno-esta-na-mesa/

12. Vital, N. Agradeça aos agrotóxicos por estar vivo. Ed. Record. 252 p. 2017.

13. Araújo, S. L. "Introdução à toxicologia". In: Curso de Verão em Farmacologia, III. Paraná, fev. 2011. Anais eletrônicos. Disponível em: http:// insightltda.com.br/images/dinamica/pdf_7fe1310c8e894324299fcfd3b8f760ef.pdf> Acesso em: 10 de setembro de 2012.

14. Brasil. Decreto No 4.074/2002 (Decreto do Executivo) 04/01/2002. Regulamenta a Lei № 7.802, de 11 de julho de 1989. Disponível em: 〈http://www.planalto.gov.br/ccivil_03/decreto/2002/D4074.htm〉. Acesso em: 14 de julho de 2017.

15. Brasil - Mapa. "XLVII - produto fitossanitário com uso aprovado para a agricultura orgânica - agrotóxico ou afim contendo exclusivamente substâncias permitidas, em regulamento próprio, para uso na agricultura orgânica". Disponível em: http://www.agricultura.gov. br/assuntos/sustentabilidade/organicos/produtos-fitossanitarios. Acesso em 15 de julho de 2017.

16. Matos, S. S. Análise das intoxicações exógenas por agrotóxicos no Brasil, entre 2007 a 2012. Trabalho de conclusão de curso apresentado à Faculdade de Ceilândia UnB/FCE, como requisito parcial para obtenção do grau de bacharel em saúde coletiva da Universidade de Brasília. 2013. Disponível em: http://bdm.unb.br/bitstream/10483/6913/1/2013_AntonioDaSilvaMatos.pdf. Acesso em: 14 de julho de 2017.

17. Aquino, Y.M.; Rohlfs, D.B. "Intoxicações por agrotóxicos no Brasil: o papel da vigilância em saúde". Disponível em: http://www.cpgls.pucgoias.edu.br/8mostra/Artigos/SAUDE\%20E\%20BIOLOGICAS/Intoxica\%C3\%A7\%C3\%B5es\%20por\%20agrot\%C3\%B3xicos\%20 no\%20Brasil\%20o\%20papel\%20da\%20vigil\%C3\%A2ncia\%20 em\%20sa\%C3\%BAde.pdf. Acessado em: 14 de setembro de 2017. 